\title{
Relação cálcio:magnésio do corretivo da acidez do solo na nutrição \\ e no desenvolvimento inicial de plantas de milho em um Cambissolo Húmico Álico
}

\section{Calcium:magnesium ratio in amendments of soil acidity: nutrition and initial development of corn plants in a Humic Alic Cambisol}

\author{
João Carlos Medeiros ${ }^{1}$; Jackson Adriano Albuquerque ${ }^{2}$; Álvaro Luiz Mafra²; \\ Jaqueline Dalla Rosa ${ }^{1}$; Luciano Colpo Gatiboni ${ }^{3}$
}

\section{Resumo}

\begin{abstract}
A variação na relação Ca:Mg em corretivos da acidez do solo é uma das principais formas de alterar a disponibilidade desses nutrientes às plantas em solos ácidos. $\mathrm{O}$ objetivo do trabalho foi avaliar o efeito de diferentes proporções entre cálcio e magnésio na forma de $\mathrm{CaCO}_{3}$ e $\mathrm{MgCO}_{3}$ sobre a absorção de nutrientes e produção inicial de matéria seca de plantas de milho. O estudo o foi desenvolvido em casa de vegetação, em Lages-SC, com delineamento experimental inteiramente casualizado e três repetições. Os tratamentos consistiram na aplicação de dose equivalente a 21,0 t ha $\mathrm{a}^{-1}$ de calcário, usando misturas de $\mathrm{CaCO}_{3}$ e $\mathrm{MgCO}_{3}$ em diversas proporções até atingir relações Ca:Mg de 1:1, 2:1, 4:1, 8:1, 16:1 e 32:1, aplicadas num Cambissolo Húmico Álico, com $310 \mathrm{~g} \mathrm{~kg}^{-1}$ de argila. A aplicação dos diferentes tratamentos elevou as relações $\mathrm{Ca}: \mathrm{Mg}$ no complexo de troca do solo para 1,1:1, 2,1:1, 4,0:1, 8,1:1, 16,4:1 e 31,8:1. As elevadas concentrações de Ca trocável no solo provocadas pela adição dos corretivos da acidez com alta relação Ca:Mg inibiram a absorção de $\mathrm{Mg}$ e $\mathrm{K}$ pelas plantas de milho. O aumento da relação Ca:Mg no solo diminuiu a produção de matéria seca e altura de plantas no estádio inicial de desenvolvimento.
\end{abstract}

Palavras-chave: Calagem, fertilidade do solo, nutrientes, Zea mays

\begin{abstract}
The variation in the Ca:Mg ratio in amendments used to neutralize soil acidity is one way of altering the availability of those nutrients to the plants in acid soils. The objective of the work was to evaluate the effect of different proportions of calcium and magnesium in the form of $\mathrm{CaCO}_{3}$ and $\mathrm{MgCO}_{3}$ on the nutrient uptake, and initial production of dry matter by corn plants. The study was carried out in greenhouse conditions, in Lages, SC, with a completely randomized experimental design, with three replications. The treatments were the application of equivalent to $21.0 \mathrm{t} \mathrm{ha}^{-1}$ of lime, using mixtures of $\mathrm{CaCO}_{3}$ and $\mathrm{MgCO}_{3}$ in several proportions to obtain different $\mathrm{Ca}$ :Mg ratios (1:1, 2:1, 4:1, 8:1, 16:1 and 32:1), on a Humic Alic Cambisol, with $310 \mathrm{~g} \mathrm{~kg}^{-1}$ of clay. The application of treatments caused the following Ca:Mg ratios in the CEC: 1.1:1, 2.1:1, 4.0:1, 8.1:1, 16.4:1 and 31.8:1. The high concentrations of exchangeable $\mathrm{Ca}$ in soil caused by addition of lime with high $\mathrm{Ca}$ content inhibited the uptake of $\mathrm{Mg}$ and $\mathrm{K}$ by the corn plants. The increase in the soil $\mathrm{Ca}: \mathrm{Mg}$ ratio reduced the dry matter production and height of plants in the initial stage of development.
\end{abstract}

Key words: Liming, nutrients, soil fertility. Zea mays

${ }_{1}$ MSc., Doutorando em Solos e Nutrição de Plantas USP/ESALQ

2 Professor, Dr. Departamento de Solos e Recursos Naturais, UDESC. Lages (SC). E-mail: a2alm@cav.udesc.br

3 Professor, Dr. Departamento de Solos e Recursos naturais, UDESC Lages (SC). Pesquisador do CNPq

* Autor para correspondência 


\section{Introdução}

O desenvolvimento e desempenho produtivo das culturas agrícolas em solos ácidos e dessaturados pode ser limitado em virtude da deficiência de elementos como $\mathrm{Ca}, \mathrm{Mg}$ e $\mathrm{K}$, mostrando resposta à adição de corretivos e fertilizantes que contenham tais nutrientes (ERNANI; NASCIMENTO; OLIVEIRA, 1998). Por outro lado, o uso de corretivos da acidez com teores de magnésio muito baixos pode restringir efeitos benéficos esperados com a correção da acidez por provocar desbalanço nutricional na planta (ROSOLEM; MACHADO; BRINHOLI, 1984). Com isso, os corretivos devem ser escolhidos não apenas por seu poder de neutralização da acidez, mas também pela proporção entre cátions acompanhantes, principalmente relação entre cálcio e magnésio no material. Esta preocupação é pertinente, especialmente em algumas regiões agrícolas no sul do Brasil, que dispõem de resíduos alcalinos da indústria de papel e celulose, compostos basicamente por óxidos e hidróxidos de cálcio e muito pobres em magnésio, sendo empregados muitas vezes de forma indiscriminada como corretivos da acidez do solo (ALBUQUERQUE et al., 2002).

A inter-relação entre os nutrientes cálcio e magnésio na nutrição vegetal está relacionada às suas propriedades químicas próximas, como o raio iônico, valência, grau de hidratação e mobilidade, fazendo com que haja competição pelos sítios de adsorção no solo, e na absorção pelas raízes. Como conseqüência, a presença de um pode prejudicar os processos de adsorção e absorção do outro, fato ocorrente para os íons $\mathrm{Ca}^{+2}$ e $\mathrm{Mg}^{+2}$ (ORLANDO FILHO et al., 1996). Num estudo realizado em casa de vegetação num Neossolo Quartzarênico com apicação de corretivo com relações $\mathrm{Ca}: \mathrm{Mg}$ crescentes, observou-se que as relações mais altas aumentaram o teor de $\mathrm{Ca}$ e diminuíram o de $\mathrm{Mg}$ e fósforo no tecido vegetal do milho, possivelmente em razão do efeito sinergético entre $\mathrm{Pe} \mathrm{Mg}$ (MUNOZ HERNANDEZ; SILVEIRA, 1998).
Em termos de resposta das culturas agrícolas às relações entre cátions básicos no solo, verificou-se que relações equilibradas dos elementos $\mathrm{Ca}, \mathrm{Mg}$ e $\mathrm{K}$ no complexo de troca de um Latossolo Distroférrico de Cambé, PR aumentou a produtividade da cultura da soja (WATANABE et al., 2005). Já para a cultura do milho em solos do cerrado, os melhores rendimentos foram obtidos com uma relação Ca:Mg de 3:1, segundo estudos realizados por (SILVA, 1980). Por outro lado, Kopittke e Menzier (2007) alertam que em solos dos Estados Unidos verificouse que variações nas relações entre cátions $\mathrm{Ca}, \mathrm{Mg}$ e K, quando não extremas, não afetam a qualidade química do solo e o crescimento das plantas.

Historicamente, o estabelecimento de relações ideais para as plantas entre os cátions básicos parece ter sido desenvolvido a partir do trabalho de Bear e Toth (1948), que usaram vinte solos dos EUA e estabeleceram que as relações Ca:Mg, Ca:K e Mg:K ideais seriam de 6,5:1, 13:1 e 2:1, respectivamente. Atualmente, a maioria dos trabalhos considera relações $\mathrm{Ca}: \mathrm{Mg}$ entre 4:1 e 8:1 como adequadas para as plantas.

Embora estabelecidas as relações $\mathrm{Ca}: \mathrm{Mg}$ ideais para as plantas, não está claramente estabelecido ainda a partir de que proporção destes elementos na CTC começam a ocorrer problemas nutricionais nas plantas. Adicionalmente, se forem consideradas as variações que ocorrem em termos de resposta à disponibilidade de cátions básicos para as culturas agrícolas, especialmente nas condições de solos ácidos, desenvolveu-se o presente estudo, com o objetivo de avaliar o efeito de diferentes relações entre cálcio e magnésio em corretivos da acidez aplicados a um solo com alto tamponamento de $\mathrm{pH}$ sobre a absorção de nutrientes e produção inicial de matéria seca de plantas de milho.

\section{Material e Métodos}

O experimento foi conduzido em casa de vegetação, em Lages(SC), utilizando um Cambissolo 
Húmico Álico, coletado na camada de $0-20 \mathrm{~cm}$ de profundidade, em áreas de vegetação campestre nativa. As principais características químicas do solo foram determinadas segundo metodologias descritas por Tedesco et al. (1995), obtendo-se os seguintes resultados: $\mathrm{pH}$ em água (1:1): 4,1; índice SMP: 4,4; P disponível por Mehlich 1: 4,0 $\mathrm{mg} \mathrm{dm}^{-3}$; K extraível por Mehlich 1: $110 \mathrm{mg} \mathrm{dm}^{-3}$; $\mathrm{Ca}, \mathrm{Mg}$ e Al trocáveis extraídos por $\mathrm{KCl} 1 \mathrm{M}: 1,8 \mathrm{cmol}_{\mathrm{c}} \mathrm{dm}^{-3}, 0,8 \mathrm{cmol}_{\mathrm{c}}$ $\mathrm{dm}^{-3}$ e $6,2 \mathrm{cmol}_{\mathrm{c}} \mathrm{dm}^{-3}$, respectivamente; matéria orgânica mensurada por oxidação sulfocrômica: 45 $\mathrm{g} \mathrm{dm}^{-3}$; teor de argila (método densimétrico): $310 \mathrm{~g}$ $\mathrm{kg}^{-1}$ e; CTC efetiva: $9,1 \mathrm{cmol}_{\mathrm{c}} \mathrm{dm}^{-3}$.

Os tratamentos constaram de relações molares entre $\mathrm{Ca}$ e $\mathrm{Mg}$ de $1: 1,2: 1,4: 1,8: 1,16: 1$ e 32:1, obtidas a partir da mistura dos corretivos $\mathrm{CaCO}_{3}$ e $\mathrm{MgCO}_{3}$. Para todos os tratamentos, a quantidade de corretivo aplicada foi equivalente a $21 \mathrm{t} \mathrm{ha}^{-1} \mathrm{de}$ calcário, que foi a necessidade estimada pelo índice SMP para elevar o pH do solo a 6,0 (COMISSÃO DE QUÍMICA E DE FERTILIDADE DO SOLO, 2004). As unidades experimentais consistiram de vasos com 3,8 $\mathrm{kg}$ de solo (base seca), passado em peneira de $2 \mathrm{~mm}$, com três repetições, em delineamento completamente casualizado. As doses de corretivos foram incorporadas ao solo 40 dias antes da semeadura do milho e incubadas à temperatura ambiente com umidade próximo à capacidade de campo.

Acultura teste foi milho(Zea mays L.), utilizandose o híbrido simples AG1560, implantada com oito sementes por vaso. A adubação, misturada ao solo antes da semeadura, consistiu de $130 \mathrm{mg} \mathrm{kg}^{-1}$ de $\mathrm{K}$, na forma de cloreto de potássio e $150 \mathrm{mg} \mathrm{kg}^{-1}$ de P na forma de MAP. O desbaste foi realizado 12 dias após a germinação, deixando três plantas por vaso. Como adubação de cobertura utilizou-se 75 $\mathrm{mg} \mathrm{kg}{ }^{-1}$ de $\mathrm{N}$ na forma de uréia, aplicada 15 dias após a germinação. A umidade do solo foi mantida

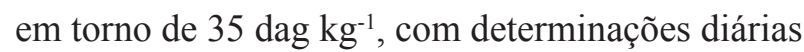
da massa e reposição da água evapotranspirada. Aos 45 dias de cultivo, as plantas foram medidas quanto a altura e cortadas rente à superfície do solo.
$\mathrm{O}$ material vegetal foi seco em estufa à $65^{\circ} \mathrm{C}$ até massa constante, determinando-se a produção de matéria seca da parte aérea. O tecido vegetal foi processado em moinho de facas, com posterior digestão sulfúrica e determinação dos teores de cálcio e magnésio por espectrofotometria de absorção atômica; teores de potássio por espectrofotometria de emissão de chama e fósforo por espectrofotometria de absorção molecular. No solo foram analisados os teores de $\mathrm{Ca}, \mathrm{Mg}$ e $\mathrm{Al}$ trocáveis, $\mathrm{P}$ e $\mathrm{K}$ disponíveis por Mehlich 1 e pH em água, seguindo metodologias descritas em Tedesco et al. (1995).

A saturação da CTC efetiva por cálcio foi calculada pela equação: [Sat ${ }_{\mathrm{Ca}}=\left(\mathrm{Ca}^{2+} / \mathrm{CTC}_{\mathrm{ef}}\right) * 100$ ], onde $\mathrm{Ca}^{2+}$ é o teor de cálcio trocável e $\mathrm{CTC}_{\mathrm{ef}}$ é a capacidade de troca catiônica efetiva do solo, ambos em $\mathrm{cmol}_{\mathrm{c}} \mathrm{dm}^{-3}$. A saturação por magnésio foi calculada de modo similar, substituindo-se os teores de $\mathrm{Ca}^{2+}$ por $\mathrm{Mg}^{2+}$.

Os resultados foram submetidos à análise de variância pelo teste $F$, e quando observados efeitos significativos, foram ajustadas as equações de regressão a partir das relações de $\mathrm{Ca}$ e $\mathrm{Mg}$.

\section{Resultados e Discussão}

A aplicação dos corretivos da acidez com diferentes relações Ca: $\mathrm{Mg}$ elevou o $\mathrm{pH}$ em água do solo de 4,1 para 6,1, não havendo diferença significativa entre os corretivos com diferentes relações $\mathrm{Ca}: \mathrm{Mg}$ usados (Tabela 1 ), indicando que quando o cálculo da dose de corretivo é feito com base nas quantidades molares de hidroxilas a serem geradas pela reação, a capacidade de correção da acidez do solo pelos materiais é semelhante, independente de suas proporções de cálcio e magnésio. 
Tabela 1. Características químicas de um Cambissolo Húmico Álico com o uso de corretivos com diferentes relações cálcio:magnésio.

\begin{tabular}{|c|c|c|c|c|c|c|c|}
\hline & \multicolumn{6}{|c|}{ Relação Ca:Mg do corretivo } & \multirow[t]{2}{*}{ Equação } \\
\hline & $1: 1$ & $2: 1$ & $4: 1$ & $8: 1$ & $16: 1$ & $32: 1$ & \\
\hline $\begin{array}{c}\mathrm{pH}-\mathrm{H}_{2} \mathrm{O} \\
(1: 1)\end{array}$ & 6,1 & 6,1 & 6,1 & 6,1 & 6,1 & 6,1 & $\mathrm{~ns}^{3}$ \\
\hline $\begin{array}{l}\text { Ca }^{+2} \text { trocável } \\
\left(\mathrm{cmol}_{\mathbf{c}} \mathbf{d m}^{-3}\right)\end{array}$ & 6,2 & 9,0 & 12,6 & 17,4 & 19,6 & 24,5 & $\begin{array}{c}\mathrm{Y}=6,57+1,33 \mathrm{x}-0,023 \mathrm{x}^{2} \\
\left(\mathrm{R}^{2}=0,96\right)^{*}\end{array}$ \\
\hline $\begin{array}{l}\mathbf{M g}^{+2} \text { trocável } \\
\left(\mathrm{cmol}_{\mathbf{c}} \mathbf{d m}^{-3}\right)\end{array}$ & 5,7 & 4,3 & 3,1 & 2,2 & 1,2 & 0,8 & $\begin{array}{c}\mathrm{Y}=5,37-0,44 \mathrm{x}+0,009 \mathrm{x}^{2} \\
\left(\mathrm{R}^{2}=0,93\right)^{*}\end{array}$ \\
\hline $\begin{array}{l}\mathrm{K}^{+} \text {trocável } \\
\left(\mathrm{cmol}_{\mathbf{c}} \mathbf{d m}^{-3}\right)\end{array}$ & 0,27 & 0,29 & 0,37 & 0,28 & 0,30 & 0,29 & ns \\
\hline $\begin{array}{l}\text { Sat }_{\mathrm{Ca}}{ }^{1} \\
(\%)\end{array}$ & 49,4 & 64,4 & 74,9 & 86,2 & 91,4 & 94,5 & $\begin{array}{c}\mathrm{Y}=53,9+4,17-0,092 \mathrm{x}^{2} \\
\left(\mathrm{R}^{2}=0,89\right)^{*}\end{array}$ \\
\hline $\begin{array}{c}\mathrm{Sat}_{\mathrm{Mg}}{ }^{2} \\
(\%)^{2}\end{array}$ & 45,3 & 30,9 & 18,7 & 10,7 & 5,5 & 3,0 & $\begin{array}{c}\mathrm{Y}=40,4-3,91 \mathrm{x}+0,09 \mathrm{x}^{2} \\
\left(\mathrm{R}^{2}=0,89\right)^{*}\end{array}$ \\
\hline $\begin{array}{l}\text { Relação Ca:Mg } \\
\text { (mol/mol) }\end{array}$ & 1,1 & 2,1 & 4,0 & 8,1 & 16,5 & 31,8 & $\begin{array}{c}\mathrm{Y}=-0,01+1,05 \mathrm{x} \\
\quad\left(\mathrm{R}^{2}=0,99\right)^{*}\end{array}$ \\
\hline
\end{tabular}

${ }^{1 /} \mathrm{Sat}_{\mathrm{Ca}}=$ saturação da CTC com cálcio; ${ }^{2 /} \mathrm{Sat}_{\mathrm{Mg}}=$ saturação da CTC com magnésio; ${ }^{* /}$ significativo $(\mathrm{P}<0,05) ;{ }^{3 /} \mathrm{ns}=$ não significativo $(\mathrm{P}>0,05)$.

Os teores de Ca trocável no solo variaram de forma quadrática, partindo de $6,2 \mathrm{cmol}_{\mathrm{c}} \mathrm{dm}^{-3}$ no tratamento com menor relação $\mathrm{Ca}: \mathrm{Mg}$, atingindo $24,5 \mathrm{cmol}_{\mathrm{c}} \mathrm{dm}^{-3}$ no ponto de máxima, obtido na relação 23:1 (Tabela 1). Já os teores de $\mathrm{Mg}$ trocável no solo responderam de maneira inversa ao observado com cálcio, diminuindo a medida que se aumentou a relação $\mathrm{Ca}: \mathrm{Mg}$ nos corretivos. Os valores observados variaram de 0,8 a $5,7 \mathrm{cmol}_{\text {c }}$ $\mathrm{dm}^{-3}$ da maior para a menor relação $\mathrm{Ca}: \mathrm{Mg}$ testada, respectivamente (Tabela 1). Adams e Hederson (1962) citam diminuição na disponibilidade e no aproveitamento do $\mathrm{Mg}$, quando o $\mathrm{pH}$ do solo é elevado pela adição de carbonato de cálcio. A variação na disponibilidade de $\mathrm{Mg}$ no solo foi relatada por Balbinot Júnior et al. (2006), que sugerem possível deficiência deste elemento em solos tratados com resíduos da indústria de papel que possuem relação $\mathrm{Ca}: \mathrm{Mg}$ elevada. Neste caso, o aproveitamento do poder corretivo destes resíduos seria indicado principalmente para solos bem supridos em $\mathrm{Mg}$, pela adição conjunta com calcário dolomítico e/ou para culturas exigentes em $\mathrm{Ca}$.
A relação Ca:Mg na CTC do solo, variou de 1,1 a 31,8 com resposta linear positiva aos valores da relação destes elementos nos corretivos aplicados ao solo. A saturação do solo com cálcio apresentou comportamento quadrático, sendo que os valores variaram de 49,4 \% para a menor relação Ca:Mg até $94 \%$ para a maior (Tabela 1). Já a saturação do solo com magnésio apresentou comportamento contrário, ou seja, diminuiu conforme aumentou a relação entre $\mathrm{Ca}$ e $\mathrm{Mg}$, variando de $45 \%$ nas maiores relações a $3 \%$ nas menores, comportamento esse esperado em função da quantidade desses cátions que são adicionados pelos corretivos em cada relação. Contudo, Key, Kurtz e Tucker (1961) observaram que a saturação com $\mathrm{Mg}$ no solo tem pouca influência na quantidade de $\mathrm{Mg}$ absorvida pela planta, considerando o $\mathrm{Mg}$ trocável como um índice de disponibilidade mais satisfatório.

Os teores de $\mathrm{K}$ extraídos do solo não diferiram entre os tratamentos, e os valores observados foram altos em todos os tratamentos, variando de 0,27 a 0,37 $\mathrm{cmol}_{\mathrm{c}} \mathrm{dm}^{-3}$ (Tabela 1), o que pode ser explicado pela adubação realizada na implantação do experimento. 
Os teores de fósforo disponível no solo variaram de 64 a $70 \mathrm{mg} \mathrm{dm}^{-3}$ (dados não apresentados), não sendo afetados significativamente pelos tratamentos.

A concentração de Ca na parte aérea do milho variou de 1,2 a $3,2 \mathrm{~g} \mathrm{~kg}^{-1}$, mostrando acúmulo deste elemento no tecido, com resposta quadrática à relação $\mathrm{Ca}: \mathrm{Mg}$ do corretivo aplicado (Tabela 2). Tal comportamento era esperado em função das quantidades crescentes de $\mathrm{Ca}$ que foram adicionadas pelos tratamentos. Entretanto, os teores de Ca no tecido ficaram abaixo do mínimo adequado para esta cultura, segundo Pauletti (2004), principalmente nas relações mais baixas. O acúmulo preferencial de cálcio pelas plantas se deu, provavelmente, porque a maior disponibilidade de cálcio no solo provocou sua aproximação às raízes em maior quantidade e, como o cálcio, magnésio e potássio são absorvidos pelos mesmos mecanismos na membrana celular, provavelmente sua absorção foi preferencial aos demais cátions estudados. Isso foi observado por Moore, Overstreet e Jacobson (1961), onde o excesso de $\mathrm{Ca}$ em relação ao $\mathrm{Mg}$ na solução do solo prejudicou a absorção deste último, e vice-versa. Resultados semelhantes também foram obtidos por Gomes et al., (2002), que conduziram experimento com diferentes relações $\mathrm{Ca}: \mathrm{Mg}$ em casa de vegetação utilizando a alfafa como cultura teste, observaram que à medida que aumentava esta relação havia acréscimo nos teores de Ca na parte aérea.

Tabela 2. Quantidade de nutrientes absorvidos pelas plantas de milho submetidas à aplicação de corretivos de acidez com diferentes relações cálcio:magnésio em um Cambissolo Húmico Álico.

\begin{tabular}{|c|c|c|c|c|c|c|c|}
\hline & \multicolumn{6}{|c|}{ Relação Ca:Mg do corretivo } & \multirow[t]{2}{*}{ Equação } \\
\hline & $1: 1$ & $2: 1$ & $4: 1$ & $8: 1$ & 16:1 & $32: 1$ & \\
\hline $\begin{array}{c}\mathrm{Ca}^{+2} \text { absorvido } \\
\mathrm{g} \mathrm{kg}^{-1}\end{array}$ & 1,2 & 1,7 & 2,1 & 2,5 & 2,6 & 3,2 & $\begin{array}{c}\mathrm{Y}=1,38+0,13 \mathrm{x}-0,002 \mathrm{x}^{2} \\
\left(\mathrm{R}^{2}=0,91\right)^{*}\end{array}$ \\
\hline $\begin{array}{c}\mathrm{Mg}^{+2} \text { absorvido } \\
\mathrm{g} \mathrm{kg}^{-1}\end{array}$ & 2,2 & 1,8 & 1,6 & 1,1 & 0,9 & 0,9 & $\begin{array}{c}\mathrm{Y}=2,13-0,13 \mathrm{x}-0,007 \mathrm{x}^{2} \\
\left(\mathrm{R}^{2}=0,94\right)^{*}\end{array}$ \\
\hline $\begin{array}{l}\mathrm{K}^{+} \text {absorvido } \\
\mathrm{g} \mathrm{kg}^{-1}\end{array}$ & 33,0 & 33,5 & 33,0 & 32,0 & 29,5 & 25,0 & $\begin{array}{c}\mathrm{Y}=33,8-0,27 \mathrm{x} \\
\quad\left(\mathrm{R}^{2}=0,99\right)^{*}\end{array}$ \\
\hline $\begin{array}{c}\text { Relação Ca:Mg } \\
(\mathbf{m o l} / \mathbf{m o l})\end{array}$ & 0,33 & 0,57 & 0,80 & 1,38 & 1,76 & 2,16 & $\begin{array}{c}\mathrm{Y}=0,28+0,14 \mathrm{x}-0,003 \mathrm{x}^{2} \\
\left(\mathrm{R}^{2}=0,98\right)^{*}\end{array}$ \\
\hline
\end{tabular}

*/ significativo $(\mathrm{P}<0,05) . \mathrm{Y}=$ variáveis do solo; $\mathrm{X}=$ relações Ca:Mg do corretivo

Os teores de $\mathrm{Mg}$ no tecido vegetal variaram de 0,9 a $2,2 \mathrm{~g} \mathrm{~kg}^{-1}$, decrescendo as concentrações com o aumento da relação Ca:Mg do corretivo, com resposta quadrática (Tabela 2). Isto demonstra que o aumento da absorção de Ca reduziu a absorção de $\mathrm{Mg}$, comportamento explicado pelo antagonismo entre estes dois elementos, levando à deficiência de Mg na parte aérea das plantas de milho. Tal antagonismo entre $\mathrm{Ca}$ e $\mathrm{Mg}$ implica que o excesso de um desses elementos diminui a absorção do outro (FOX; PIEKIELEK, 1984). Estes resultados já foram encontrados em outros estudos, onde se observou redução nos teores de $\mathrm{Mg}$ no tecido de soja e milho (KEY; KURTZ; TUCKER, 1961) e em cebola (LIEROP; MARTEL; CESCAS, 1979) na medida em que aumentavam as relações $\mathrm{Ca}: \mathrm{Mg}$ no solo. Ainda, os valores observados para o elemento $\mathrm{Mg}$ ficaram abaixo do mínimo adequado para a cultura do milho, e somente nas menores relações observouse teor adequado para este nutriente (PAULETTI, 2004). Contudo, há que se tomar cuidado na interpretação dos teores de nutrientes na parte aérea 
de milho do presente experimento em relação aos teores considerados adequados pela literatura, já que normalmente aqueles tratam de plantas adultas, enquanto que no presente experimento a análise foi realizada em plantas com 45 dias de crescimento.

A relação $\mathrm{Ca}: \mathrm{Mg}$ no tecido vegetal comportouse de forma quadrática, aumentando com a elevação da relação entre estes elementos nos tratamentos (Tabela 2). O aumento na relação entre $\mathrm{Ca}: \mathrm{Mg}$ no tecido vegetal esteve bem abaixo desta relação no solo, principalmente nas maiores relações, pois no solo o acréscimo foi linear e no tecido este incremento foi quadrático. Isso indica que as plantas tendem a compensar o desbalanço do solo, minimizando os efeitos deletérios de discrepâncias nas relações entre esses nutrientes ou, ainda, a grande concentração de cálcio que chega até as raízes provoca a saturação dos carregadores na membrana, impedindo sua absorção nas mesmas proporções existentes no solo. No presente estudo a relação $\mathrm{Ca}: \mathrm{Mg}$ no tecido em relação ao solo diminuiu para 30 e $7 \%$ dos valores de relações $\mathrm{Ca}: \mathrm{Mg}$ existentes no solo, para os tratamentos 1:1 e 32:1, respectivamente. Esse fenômeno também foi observado por Simson, Corey e Sumner (1979) em um experimento testando o efeito da relação $\mathrm{Ca}: \mathrm{Mg}$ em plantas de milho e alfafa, onde encontraram que a relação no tecido foi de aproximadamente $1 / 3$ da relação $\mathrm{Ca}: \mathrm{Mg}$ dos sítios de troca do solo. Também Oliveira e Parra (2003) citam que as relações $\mathrm{Ca}: \mathrm{Mg}$ no tecido da parte aérea do feijoeiro foram influenciadas pelas relações $\mathrm{Ca}: \mathrm{Mg}$ dos solos, porém, não na mesma proporção.

A concentração de potássio na parte aérea das plantas decresceu linearmente com o aumento da relação $\mathrm{Ca}: \mathrm{Mg}$ do corretivo da acidez (Tabela 2), partindo de $33 \mathrm{~g} \mathrm{~kg}^{-1}$ na maior relação $\mathrm{Ca}: \mathrm{Mg}$ e atingindo $25 \mathrm{~g} \mathrm{~kg}^{-1}$ na menor. Isso confirma o efeito antagônico entre $\mathrm{K}$ e $\mathrm{Ca}$ em função das altas quantidades de $\mathrm{Ca}$ adicionadas, como verificado também por Pintro et al. (2005).

A altura das plantas de milho reduziu linearmente em função do aumento na relação $\mathrm{Ca}: \mathrm{Mg}$ (Figura 1a). Comportamento similar ocorreu com a produção de matéria seca das plantas, que decresceu com o aumento da relação entre esses nutrientes (Figura 1b). A redução no desenvolvimento das plantas, nesse caso, pode ser explicada pelo desequilíbrio de nutrientes à medida que a relação $\mathrm{Ca}: \mathrm{Mg}$ aumenta, especialmente para magnésio e potássio, que são prejudicados pelo excesso de cálcio absorvido pelas plantas (MARSCHNER, 1999). Esses resultados conferem com os de Munoz Hernandez e Silveira (1998) que em estudo realizado em casa de vegetação num Neossolo Quartzarênico, observaram influência negativa na produção de matéria seca do milho em função do aumento da relação $\mathrm{Ca}: \mathrm{Mg}$ do solo, sendo que as relações $\mathrm{Ca}: \mathrm{Mg}$ maiores que 3:1 causaram quedas no crescimento e na produção das plantas. No presente trabalho, relações $\mathrm{Ca}: \mathrm{Mg}$ de até 8:1 parecem ter afetado pouco o desempenho das plantas, havendo problemas visíveis nas relações 16:1 e 32:1 (Figura 1).

Os resultados apresentados mostram que pode ocorrer modificação drástica da relação $\mathrm{Ca}: \mathrm{Mg}$ na CTC do solo, provocada pela adição de corretivos da acidez do solo com altas concentrações de cálcio em relação ao magnésio. O aumento da saturação do solo por cálcio pode causar absorção preferencial deste pelas plantas, em detrimento dos íons magnésio e potássio, e provocar desbalanço nutricional, diminuindo a altura e produção de matéria seca de plantas de milho em fase inicial de crescimento. Assim, na região do Planalto Catarinense, que possui solos que necessitam elevadas quantidades de corretivos da acidez em virtude dos altos teores de matéria orgânica e acidez potencial, deve-se ter cautela na escolha do corretivo da acidez a ser utilizado, pois materiais com elevada relação Ca:Mg podem afetar negativamente a produtividade das culturas. 
(a)

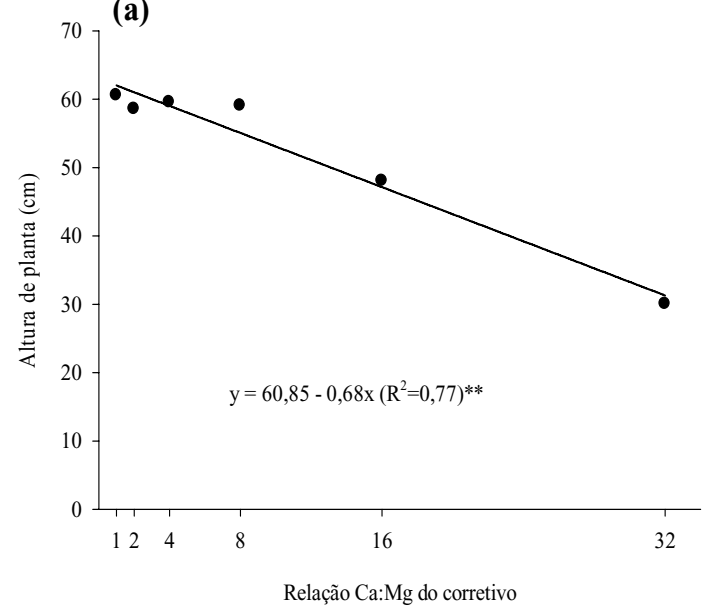

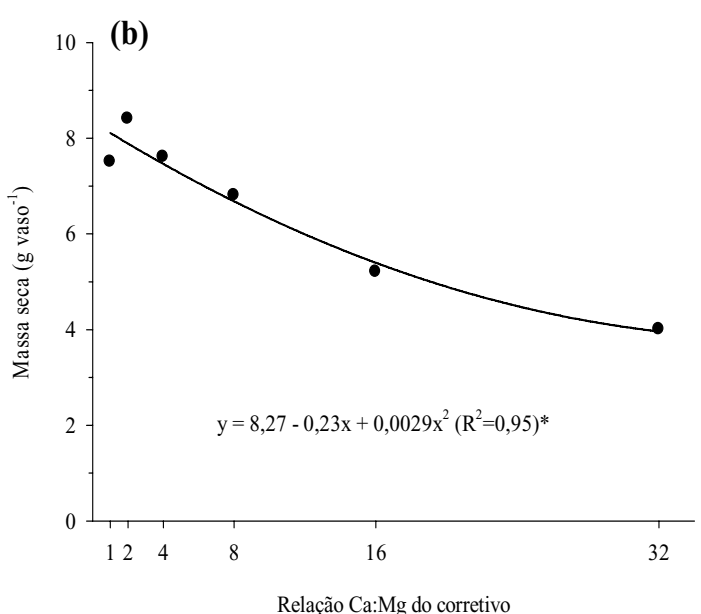

Figura 1. Altura de plantas de milho em estágio inicial de desenvolvimento (a) e produção de massa seca (b) em Cambissolo Húmico Álico submetido à aplicação de corretivos da acidez com relações Ca: $\mathrm{Mg}$ crescentes $(* *=$ $\mathrm{P}<0,01 ; * \mathrm{P}<0,05)$.

\section{Conclusões}

1. A aplicação de corretivos da acidez com crescentes proporções de cálcio em relação ao magnésio aumentou o teor e a saturação de cálcio na CTC do solo, não afetou os teores de potássio e reduziu os de magnésio.

2. Elevadas concentrações de Ca trocável no solo provocadas pela aplicação de corretivos da acidez do solo com alta relação $\mathrm{Ca}: \mathrm{Mg}$ diminuíram a absorção de magnésio e potássio pelas plantas de milho.

2. A produção de matéria seca e a altura de plantas de milho no estádio inicial de desenvolvimento decresceram com o aumento da relação $\mathrm{Ca}: \mathrm{Mg}$ no solo.

\section{Referências}

ADAMS, F.; HENDERSON, J. B. Magnesium availability as affected by deficient and adequate levels of potassium and lime. Soil Science Society of America Proceedings, Madison, v. 26, n. 1, p. 65-68, 1962.

ALBUQUERQUE, J. A.; ARGENTON, J.; FONTANA, E. C.; COSTA, F. S.; RECH, T. D. Propriedades físicas e químicas de solos incubados com resíduo alcalino da indústria de celulose. Revista Brasileira de Ciência do Solo, Viçosa, v. 26, n. 4, p. 1065-1073, 2002.
BALBINOT JÚNIOR, A. A.; TORRES, A. N. L.; FONSECA, J. A.; TEIXEIRA, J. R.; NESI, C. N. Alteração em características químicas de um solo ácido pela aplicação de calcário e resíduos de reciclagem de papel. Revista de Ciências Agroveterinárias, Lages, v. 5, n. 1, p. 16-25, 2006.

BEAR, F. E.; TOTH, S. J. Influence of Ca on availability of other soil cations. Soil Science, Baltimore, v. 65, n. 1, p. 69-75, 1948.

COMISSÃO DE QUÍMICA E DE FERTILIDADE DO SOLO. Manual de adubação e de calagem para os estados do Rio Grande do Sul e de Santa Catarina. 10. ed. Porto Alegre: SBCS/NRS, 2004.

ERNANI, P. R.; NASCIMENTO, J. A.; OLIVEIRA, L. C. Aumento do rendimento de grãos e de massa verde de milho ocasionado pela calagem. Revista Brasileira de Ciência do Solo, Viçosa, v. 22, n. 2, p. 275-280, 1998.

FOX, R. H.; PIEKIELEK, W. P. Soil magnesium level, corn (Zea mays L.) yield, and magnesium uptake. Communications in Soil Science and Plant Analysis, Philadelphia, v. 15, n. 22, p. 109-123, 1984.

GOMES, F. T.; BORGES, A. C.; NEVES, J. C. L.; FONTES, P. C. R. Influência de doses de calcário com diferentes relações cálcio:magnésio na produção de matéria seca e na composição mineral da alfafa. Pesquisa Agropecuária Brasileira, Brasília, v. 37, n. 12, p. 17791786, 2002. 
KEY, J. L.; KURTZ, L. T.; TUCKER, B. B. Influence of ratio of exchangeable calcium magnesium on yield and composition of soybeans and corn. Soil Science, Baltimore, v. 91, n. 4, p. 265-271, 1961.

KOPITTKE, P. M.; MENZIER, N. W. A review of the use of the basic cation saturation ratio and the "ideal" soil. Soil Science Society of America Journal, Madison, v. 71, n. 2, p. 259-265, 2007.

LIEROP, W. V.; MARTEL, Y. A.; CESCAS, M. P. Onion response to lime on acid Histosols as affected by $\mathrm{Ca}: \mathrm{Mg}$ ratios. Proceedings: Soil Science Society of America, Madison, v. 43, n. 6, p. 1172-1177, 1979.

MARSCHNER, H. Mineral nutrition of higher plants. London: Academic Press, 1999.

MOORE, D. P.; OVERSTREET, R.; JACOBSON, L. Uptake of magnesium and its interactions with calcium in excised barley roots. Plant Physiology, Rockville, v. 36, n. 3, p. 290-295, 1961.

MUNOZ HERNANDEZ, R. J.; SILVEIRA, R. I. Efeito da saturação por bases, relações $\mathrm{Ca}: \mathrm{Mg}$ no solo e níveis de fósforo sobre a produção de material seco e nutrição mineral do milho (Zea mays L.). Scientia Agricola, Piracicaba, v. 55, n. 1, p. 79-85, 1998.

OLIVEIRA, E. L.; PARRA, M. S. Resposta do feijoeiro a relações variáveis entre cálcio e magnésio na capacidade de troca de cátions de latossolos. Revista Brasileira de Ciência do Solo, Viçosa, v. 27, n. 5, p. 859-866, 2003.

ORLANDO FILHO, J. O.; BITTENCOURT, V. C.; CARMELLO, Q. A. C.; BEAUCLAIR, E. G. F. Relações $\mathrm{K}, \mathrm{Ca}$ e $\mathrm{Mg}$ de solo areia quartzosa e produtividade da cana-de-açúcar. STAB: Açucar, Álccol e Subprodutos, Piracicaba, v. 14, n. 5, p. 13-17, 1996.
PAULETTI, V. Nutrientes: Teores e interpretações. 2. ed. Castro: Fundação ABC, 2004.

PINTRO, J. C.; INOUE, T. T.; TORMENA, C. A.; COSTA, A. C. S.; SILVA, M. A. G. Mineral composition and dry mass production of corn plants affected by different phosphate sources and different soil aluminum saturation levels. Journal of Plant Nutrition, Philadelphia, v. 27, n. 12 , p. 2149-2158, 2005.

ROSOLEM, C. A.; MACHADO, J. R.; BRINHOLI, O. Efeito das relações $\mathrm{Ca}: \mathrm{Mg}, \mathrm{Ca}: \mathrm{K}$ e $\mathrm{Mg}: \mathrm{K}$ do solo na produção de sorgo sacarino. Pesquisa Agropecuária Brasileira, Brasília, v. 19, n. 12, p. 1443-1448, 1984.

SILVA, J. E. Balanço de cálcio e magnésio e desenvolvimento de milho em solos de cerrado. Pesquisa Agropecuária Brasileira, Brasília, v. 15, n. 3, p. 329-333, 1980.

SIMSON, C. R.; COREY, R. B.; SUMNER. M. E. Effect of varying Ca:Mg ratios on yield and composition of corn (Zea mays) and alfalfa (Medicago sativa). Communications in Soil Science and Plant Analysis, Philadelphia, v. 10, n. 1-2, p. 153-162, 1979.

TEDESCO, M. J.; GIANELLO, C.; BISSANI, C. A.; BOHNEN, H.; VOLKWEISS, S. J. Análises de solo, plantas e outros materiais. 2. ed. Porto Alegre: UFRGS, 1995.

WATANABE, R. T.; FIORETTO, R. A.; FONSECA, J. B.; SEIFERT, A. L.; SANTIAGO, D. C.; CRESTE, J. E.; HARADA, A.; CUCOLOTTO, M. Produtividade da soja em função da densidade populacional e da porcentagem de cátions $(\mathrm{Ca}, \mathrm{Mg}$ e $\mathrm{K})$ no complexo sortivo do solo. Semina: Ciências Agrárias, Londrina, v. 26, n. 4, p. 477484, 2005. 